\title{
Palladium-Catalyzed Asymmetric Allylic Alkylation Using Ephedrine-derived Phosphinooxazolidines
}

\author{
Myung-Jong Jin, ${ }^{*}$ M. S. Sarkar, Ji-Young Jung, Dong-Hwan Lee, ${ }^{\dagger}$ and Ik-Mo Lee ${ }^{\dagger}$ \\ Department of Chemical Engineering, Inha University, Incheon 402-751, Korea. *E-mail: mjjin@inha.ac.kr \\ ${ }^{\dagger}$ Department of Chemistry, Inha University, Incheon 402-751, Korea \\ Received December 23, 2005
}

Key Words : Asymmetric catalysis, Allylic substitution, Ephedrine, Phosphinooxazolidine

Asymmetric carbon-carbon bond formation constitutes an important topic in modern organic synthesis. ${ }^{1}$ In particular, Pd-catalyzed asymmetric allylic alkylation has received considerable attention as an useful asymmetric carboncarbon forming process, in which racemic or achiral allylic substrates can be converted to optically active products in the presence of $\pi$-allylpalladium complex of chiral ligand. ${ }^{2}$ To obtain high enantioselectivity in the catalytic reaction, much efforts have been devoted to the synthesis of efficient ligands. Chiral phosphinooxazolines $\mathbf{1}$ have been extensively applied in this area. ${ }^{1 \mathrm{~d}}$ In contrast, little is known about structurally-similar oxazolidine ligands. We previously found that phosphinooxazolidine $\mathbf{2 a}$ can act as an excellent chiral ligand for the asymmetric catalysis. ${ }^{3}$ In this paper we wish to present new phosphinooxazolidines $\mathbf{3}$ and pyridinooxazolidine 4, derived from optically active ephedrine, together with their behavior as chiral ligands in the Pdcatalyzed asymmetric allylic alkylation.<smiles>[Z]C1COC(c2ccccc2P)=N1</smiles>

1

3a<smiles>C[C@H]1[C@H](c2ccccc2)O[C@@H](c2ccccc2[C@@H]2O[C@H](c3ccccn3)[C@@H](C)N2C)O[C@H]1c1ccccc1[C@@H]1O[C@H](c2ccccc2)[C@@H](C)N1C</smiles>

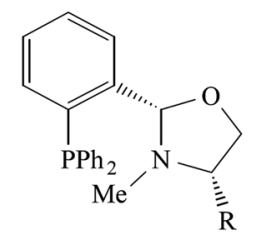

2a: $\mathrm{R}=i-\mathrm{Pr}$ 2b: $\mathrm{R}=\mathrm{Me}$
Phosphinooxazolidines $\mathbf{3 a}$ and $\mathbf{3 b}$ were readily prepared by condensation of 2-(diphenylphosphino)benzaldehyde with $(1 R, 2 S)$-ephedrine and $(1 S, 2 S)$-pseudoephedrine in refluxing benzene, respectively. Pyridinooxazolidine 4 was also obtained from 2-pyridinecarboxaldehyde and $(1 R, 2 S)$ ephedrine by the same method. The formation of oxazolidine ring proceeded diastereoselectively, in which phosphinooxazolidines 3 were obtained as diastereomer mixtures in 9 : 1 ratios and 4 was in fact diastereomerically pure within
NMR detection limits. The absolute configuration of $S$ at new $C 2$-stereogenic center was assigned on the basis of the previous studies. ${ }^{4}$ We then examined the chiral oxazolidines in the palladium-catalyzed asymmetric allylic alkylation of 1,3-diphenyl-2-propenyl acetate 5 with dimethyl malonate. This reaction was carried out in the presence of a palladium catalyst generated in situ from $\pi$-allylpalladium chloride dimer and the ligands. $N, O$-Bis(trimethylsilyl)acetamide (BSA) combined with a small amount of KOAc or NaOAc was used as a base. The reaction conditions and results are summarized in Table 1. Ligand $\mathbf{2 b}$ having methyl group at $C 4$ provided lower enantioselectivity of $86 \%$ than $2 \mathbf{a}$ having bulky isopropyl group previously reported. ${ }^{3}$ The effect of substituent at $C 5$ was examined with ephedrine-derived ligand 3a bearing phenyl group at $C 5$. Interestingly, the ee

Table 1. Allylic alkylation of 1,3-diphenyl-2-propenyl acetate with dimethyl malonate ${ }^{a}$

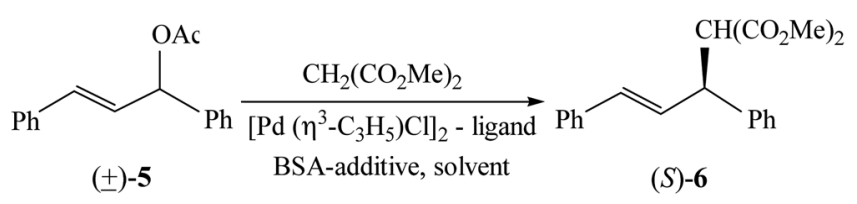

\begin{tabular}{|c|c|c|c|c|c|c|}
\hline Ligand & Solvent & Additive & $\begin{array}{c}\text { Temp. } \\
\left({ }^{\circ} \mathrm{C}\right)\end{array}$ & $\begin{array}{l}\text { Time } \\
\text { (h) }\end{array}$ & $\begin{array}{l}\text { Yield } \\
(\%)^{b}\end{array}$ & $\begin{array}{l}\text { ee } \\
(\%)^{c}\end{array}$ \\
\hline $2 b$ & THF & KOAc & 10 & 1 & 91 & 86 \\
\hline $3 \mathbf{a}$ & THF & KOAc & 10 & 1 & 92 & 95 \\
\hline $\mathbf{3} \mathbf{a}^{d}$ & THF & KOAc & 10 & 1 & 93 & 95.2 \\
\hline $3 \mathbf{a}$ & $\mathrm{CH}_{2} \mathrm{Cl}_{2}$ & KOAc & 10 & 0.8 & 98 & 91 \\
\hline $3 \mathbf{a}$ & THF & KOAc & 20 & 1 & 98 & 93 \\
\hline $3 \mathbf{a}$ & THF & $\mathrm{NaOAc}$ & 10 & 2 & 90 & 90 \\
\hline $3 \mathbf{b}$ & THF & KOAc & 20 & 1 & 99 & 84 \\
\hline $3 \mathbf{b}$ & $\mathrm{CH}_{2} \mathrm{Cl}_{2}$ & KOAc & 20 & 0.8 & 98 & 77 \\
\hline $3 b$ & THF & $\mathrm{NaOAc}$ & 20 & 1 & 97 & 82 \\
\hline 4 & THF & KOAc & 10 & 24 & 80 & 68 \\
\hline 4 & $\mathrm{CH}_{2} \mathrm{Cl}_{2}$ & KOAc & 10 & 24 & 80 & 76 \\
\hline 4 & $\mathrm{CH}_{2} \mathrm{Cl}_{2}$ & KOAc & 20 & 24 & 96 & 75 \\
\hline 4 & $\mathrm{CH}_{2} \mathrm{Cl}_{2}$ & $\mathrm{NaOAc}$ & 10 & 24 & 71 & 73 \\
\hline
\end{tabular}

${ }^{a}$ Reactions were carried out with $\left[\mathrm{Pd}\left(\eta^{3}-\mathrm{C}_{3} \mathrm{H}_{5}\right) \mathrm{Cl}\right]_{2}(2.0$ mol\%), ligand $(5$ mol\%), BSA (3 equiv.) and dimethyl malonate (3 equiv.) and a catalytic amoumt of additive. ${ }^{b}$ Measured as \% conversion into the product by GC. ${ }^{c}$ Determined by HPLC with a chiralcel OD-H column. Absolute configuration was assigned by the optical rotation and the elution order from a chiral column. ${ }^{D}$ Diasteromerically pure ligand $3 \mathbf{a}$ was used. 
was enhanced up to $95 \%$ ee. Introduction of an additional group at $C 5$ resulted in a significant increase of enantioselectivity. This substituent seems to assist the stereochemical control of the reaction. Diasteromerically pure ligand 3a gave nearly same level of $95.2 \%$ ee under the same condition. This result indicates that diasteromerically pure ligand is not necessarily required in order to obtain much higher enantioselectivity. ${ }^{5}$ This mixture itself could efficiently be used in the catalysis. Accordingly, the additional separation step of diastereomers became unnecessary and the overall process was simplified. Potassium acetate as an additive gave better results than sodium acetate. The effect of reaction temperature was detectable but not very significant at temperature between $10{ }^{\circ} \mathrm{C}$ and $20{ }^{\circ} \mathrm{C}$. In addition, THF gave higher enantioselectivity than $\mathrm{CH}_{2} \mathrm{Cl}_{2}$. Pseudoephedrine-derived ligand $\mathbf{3 b}$ was used in this reaction in order to investigate the role of the $C 5$-stereogenic center on the stereochemical outcome. Compared to ligand 3a, ligand $\mathbf{3 b}$ showed lower enantioselectivity but the configuration of the major product was same. The decreased enantioselectivity is attributed to the fact that the phenyl group with $(S)$-configuration and the methyl group with $(S)$ configuration are dismatched for the reaction. From the above results, $C 4$-stereogenic center of the oxazolidine unit has a key influence on the asymmetric induction and controls the configuration of the product. The C5stereogenic center has a minor, but still a significant effect. When pyridinooxazolidine $\mathbf{4}$ was used under the same conditions, the allylic substitution proceeded smoothly with up to $76 \%$ ee. In this case, $\mathrm{CH}_{2} \mathrm{Cl}_{2}$ seems to be a more suitable solvent than THF. $N, N$-Chelate ligand $\mathbf{4}$ was inferior in terms of enantioselectivity and reactivity to $N, P$-chelate ligand 3.

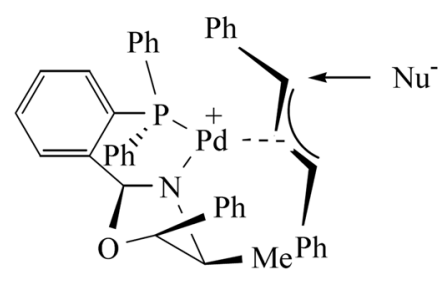

I (favoured)

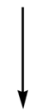

major $(S)$-product

This reaction gave predominantly $(S)$-product $\mathbf{6}$. The stereochemical outcome obtained here indicates that the nucleophilic attack to the carbon atom of the $\pi$-allyl moiety takes place preferentially at trans position to the oxazolidine nitrogen in the less sterically-hindered endo- $\pi$-allyl palladium complex (I). In the case of exo- $\pi$-allyl complex (II), severe steric repulsion is generated between phenyl group as well as methyl group on the oxazolidine ring and phenyl group in the substrate.
In conclusion, new kinds of ephedrine-based oxazolidines could be used as chiral ligands in the asymmeric Pdcatalyzed allylic alkylation. In particular, phosphinooxazolidine 3a indeed offered excellent enantioselectivity and high reactivity. It is noteworthy that phenyl group at $C 5$ of oxazolidine ring in ligand 3a exerts a beneficial influence on the enantioselectivity. Further synthesis of chiral oxazolidines and their application are in progress.

\section{Experimental Section}

Reactions were carried out under an inert nitrogen atmosphere using dried glassware. All the commercially available reagents were used without further purification. NMR spectra were recorded on a Bruker AC 250 NMR spectrometer. Optical rotation were measured with a Perkin-Elmer 241 polarimeter. Determination of optical purity was performed by HPLC analysis using chiralcel OD-H column. THF was freshly distilled over sodium benzophenone and $\mathrm{CH}_{2} \mathrm{Cl}_{2}$ was distilled over $\mathrm{CaH}_{2}$ before use.

(4S,5R)-2-[2-(Diphenylphosphino)phenyl]-3,4-dimethyl5-phenyloxazolidine 3a: To a solution of 2-(diphenylphosphino)benzaldehyde (145 mg, $0.5 \mathrm{mmol}$ ) in degassed benzene $(1.2 \mathrm{~mL}),(1 R, 2 S)$-ephedrine $(91 \mathrm{mg}, 0.55 \mathrm{mmol})$ was added. The mixture was stirred at $75^{\circ} \mathrm{C}$ for $12 \mathrm{~h}$, then concentrated under reduced pressure. The crude product was purified by short flash chromatography on silica gel pretreated with triethylamine (5\% EtOAc-5\% $\mathrm{Et}_{3} \mathrm{~N} /$ hexane) to afford 3a (208 $\mathrm{mg}, 95 \%)$ as a white powder: $[\alpha]_{\mathrm{D}}^{20}-82.3$ (c 1.0, $\left.\mathrm{CH}_{3} \mathrm{Cl}\right) ;{ }^{1} \mathrm{H} \mathrm{NMR}\left(\mathrm{CDCl}_{3}, 250 \mathrm{MHz}\right) \delta 8.01-6.82(\mathrm{~m}$, Ar), $6.01\left(\mathrm{~d},{ }^{4} J_{\mathrm{PH}^{\prime}}=7.8 \mathrm{~Hz}, \mathrm{OC} H \mathrm{~N}\right)+5.51\left(\mathrm{~d},{ }^{4} J_{\mathrm{PH}}=7.8 \mathrm{~Hz}\right.$, $\mathrm{OC} H \mathrm{~N}), 5.44\left(\mathrm{~d},{ }^{4} J_{\mathrm{PH}^{\prime}}=7.8 \mathrm{~Hz}, \mathrm{CH} \mathrm{Ph}\right)+5.05\left(\mathrm{~d},{ }^{4} J_{\mathrm{PH}}=\right.$ $10.0 \mathrm{~Hz}, \mathrm{CHPh}), 3.58\left(\mathrm{~m}, \mathrm{CH}^{\prime} \mathrm{CH}_{3}\right)+2.85\left(\mathrm{~m}, \mathrm{CHCH}_{3}\right)$, $2.00\left(\mathrm{~s}, \mathrm{NCH}_{3}^{\prime}\right)+1.85\left(\mathrm{~s}, \mathrm{NCH}_{3}\right), 0.66(\mathrm{~d}, J=13.3 \mathrm{~Hz}$, $\left.\mathrm{CCH}_{3}\right)+0.48\left(\mathrm{~d}, J=13.3 \mathrm{~Hz}, \mathrm{CCH}_{3}^{\prime}\right)$; MS (EI) $\mathrm{m} / z 437$ $\left(\mathrm{M}^{+}\right)$. $\mathrm{H}^{\prime}$ corresponds to minor diastereomer. Anal. Calcd for $\mathrm{C}_{29} \mathrm{H}_{28} \mathrm{NOP}$ : C, 79.61; H, 6.45; N, 3.20. Found: C, 79.58; H, $6.43 ; \mathrm{N}, 3.19$.

(4S,5S)-2-[2-(Diphenylphosphino)phenyl]-3,4-dimethyl5-phenyloxazolidine 3b: Similar to the above procedure, 2(diphenylphosphino) benzaldehyde (145 mg, $0.5 \mathrm{mmol}$ ) was allowed to react with $(1 S, 2 S)$-pseudoephedrine $(91 \mathrm{mg}, 0.55$ mmol) to give $3 \mathbf{b}(204 \mathrm{mg}, 93 \%)$ as a white powder: $[\alpha]_{\mathrm{D}}^{20}$ -59.3 (c 1.0, $\left.\mathrm{CH}_{3} \mathrm{Cl}\right)$; ${ }^{1} \mathrm{H} \mathrm{NMR}\left(\mathrm{CDCl}_{3}, 250 \mathrm{MHz}\right) \delta 7.78-$ $6.82(\mathrm{~m}, \mathrm{Ar}), 6.01\left(\mathrm{~d},{ }^{4} J_{\mathrm{PH}^{\prime}}=4.8 \mathrm{~Hz}, \mathrm{OCH}^{\prime} \mathrm{N}\right)+5.64\left(\mathrm{~d},{ }^{4} J_{\mathrm{PH}}\right.$ $=6.4 \mathrm{~Hz}, \mathrm{OCHN}), 4.68\left(\mathrm{~d},{ }^{4} J_{\mathrm{PH}}=8.4 \mathrm{~Hz}, \mathrm{CHPh}\right)+4.47(\mathrm{~d}$, $\left.{ }^{4} J_{\mathrm{PH}^{\prime}}=6.4 \mathrm{~Hz}, \mathrm{CH} H^{\prime} \mathrm{Ph}\right), 2.97\left(\mathrm{~m}, \mathrm{CH}^{\prime} \mathrm{CH}_{3}\right)+2.31\left(\mathrm{~m}, \mathrm{CHCH}_{3}\right)$, $2.05\left(\mathrm{~s}, \mathrm{NCH}_{3}^{\prime}\right)+1.90\left(\mathrm{~s}, \mathrm{NCH}_{3}\right), 1.11\left(\mathrm{~d}, J=6.0 \mathrm{~Hz}, \mathrm{CCH}_{3}\right)$ $+0.85\left(\mathrm{~d}, J=6.0 \mathrm{~Hz}, \mathrm{CCH}_{3}^{\prime}\right)$; $\mathrm{MS}(\mathrm{EI}) \mathrm{m} / z 437\left(\mathrm{M}^{+}\right)$. H' corresponds to minor diastereomer. Anal. Calcd for $\mathrm{C}_{29} \mathrm{H}_{28}$ NOP: C, 79.61; H, 6.45; N, 3.20. Found: C, 79.57; H, $6.43 ; \mathrm{N}, 3.17$.

(4S,5R)-2-(2-Pyridinyl)-3,4-dimethyl-5-phenyloxazolidine 4. Similar to the above procedure, 2-pyridinecarboxaldehyde (75 mg, $0.7 \mathrm{mmol})$ was allowed to react with $(1 R, 2 S)$ ephedrine (132 mg, $0.8 \mathrm{mmol})$ to give 4 (155 mg, 87\%); $[\alpha]_{\mathrm{D}}^{20}=-48.7\left(\mathrm{c} 1.2, \mathrm{CHCl}_{3}\right)$; MS: $m / \mathrm{z} 254\left(\mathrm{M}^{+}\right)$; ${ }^{1} \mathrm{H}-\mathrm{NMR}$ : 
$\left(\mathrm{CDCl}_{3}, 250 \mathrm{MHz}\right) \delta 8.62(\mathrm{~d}, J=4.8 \mathrm{~Hz}, 1 \mathrm{H}), 7.81-7.19(\mathrm{~m}$, $8 \mathrm{H}), 5.18$ (d, $J=8.1 \mathrm{~Hz}, 1 \mathrm{H}), 4.82$ (s, 1H), 3.02 (m, 1H), 2.29 (s, 3H) $0.74(\mathrm{~d}, J=6.3 \mathrm{~Hz}, 3 \mathrm{H})$; Anal. Calcd for $\mathrm{C}_{16} \mathrm{H}_{18} \mathrm{~N}_{2} \mathrm{O}: \mathrm{C}, 75.56 ; \mathrm{H}, 7.13 ; \mathrm{N}, 11.01$. Found: $\mathrm{C}, 75.51 ; \mathrm{H}$, $7.18 ; \mathrm{N}, 11.09$.

A representative procedure for asymmetric allylic alkylation. In a Schlenk tube the ligand $\mathbf{3 a}(8.7 \mathrm{mg}, 0.02$ $\mathrm{mmol})$ and allylpalladium chloride dimer $(3.0 \mathrm{mg}, 0.008$ $\mathrm{mmol})$ were dissolved in THF $(0.6 \mathrm{~mL})$ and the mixture was stirred at room temperature for $20 \mathrm{~min}$. To this solution were successively added 1,3-diphenyl-2-propenylacetate (100 $\mathrm{mg}, 0.4 \mathrm{mmol})$ in THF $(1.4 \mathrm{~mL})$, dimethyl malonate $(158$ $\mathrm{mg}, 1.56 \mathrm{mmol}$ ), $\mathrm{N}, \mathrm{O}$-bis(trimethylsilyl) acetamide (244 mg, $1.2 \mathrm{mmol}$ ) and catalytic amount of KOAc. The mixture was stirred at a given temperature. After the reaction was complete, the reaction mixture was diluted with ether $(15 \mathrm{~mL})$, washed with cold saturated aqueous ammonium chloride solution $(10 \mathrm{~mL})$. The organic layer was dried $\left(\mathrm{MgSO}_{4}\right)$ and concentrated under reduced pressure. The residue was purified by column chromatography on silica gel (15\% EtOAc/ hexane). The enantiomeric excess was determined by HPLC analysis (chiralcel OD-H column; flow rate, $0.5 \mathrm{~mL} / \mathrm{min}$; hexane : isopropanol $=99: 1$ ).
Acknowledgement. This work was supported by Inha University Research Grant (INHA-2006).

\section{References}

1. For recent reviews: (a) Ghosh, A. K.; Mathivanan, P.; Cappiello, J. Tetrahedron: Asymmetry 1998, 9, 1. (b) Pfaltz, A.; Lautens, M. In Comprehensive Asymmetric Catalysis; Jacobsen, E. N.; Pfaltzand, A.; Yamamoto, H., Eds.; Springer-Verlag: Berlin, 1999; Vol II, p 833. (c) Trost, B. M.; Crawley, M. L. Chem. Rev. 2003, 103, 2921.

2. (a) Saitoh, A.; Achiwa, K.; Tanaka, K.; Morimoto, T. J. Org. Chem. 2000, 65, 4227. (b) Stranne, R.; Vasse, J.-L.; Moberg, C. Org. Lett. 2001, 3, 2525. (c) Mino, T.; Shiotsuki, M.; Yamamoto, N.; Suenaga, T.; Sakamoto, M.; Fujita, T.; Yamashita, M. J. Org. Chem. 2001, 66, 1795. (d) Lee, Y.-H.; Kim, Y.-K.; Son, J.-H.; Ahn, K.-H. Bull. Korean Chem. Soc. 2003, 24, 225. (e) Oohara, N.; Katagiri, K.; Imamoto, T. Tetrahedron: Asymmetry 2003, 14, 2171. (f) Bayardon, J.; Sinou, D.; Guala, M.; Desimoni, G Tetrahedron: Asymmetry 2004, 15, 3195.

3. Jin, M.-J.; Jung, J.-A.; Kim, S.-H. Tetrahedron Lett. 1999, 40, 5197.

4. (a) Mangeney, P.; Alexakis, A.; Normant, J. F. Tetrahedron 1984, 40, 1803. (b) Bernardi, A.; Cardani, S.; Pilati, T.; Scolastico, C.; Villa, R. J. Org. Chem. 1988, 53, 1600. (c) Dai, W.-M.; Zhu, H. J.; Hao, X.-J. Tetrahedron: Asymmetry 1996, 7, 1245.

5. Brunner, H.; Becker, R.; Riepl, G. Organometallics 1984, 3, 1354. 